\title{
SUSCETIBILIDADE DE BIOMPHALARIA GLABRATA, VARIANTE ALBINA, ORIUNDA DE BELO HORIZONTE, MG, À INFECÇÃO POR SCHISTOSOMA MANSONI, PARASITA EM CONDIÇÕES NATURAIS, DE ROEDORES SILVESTRES DO VALE DO RIO PARAFBA DO SUL, SP (BRASIL) *
}

Othon de Carvalho Bastos** Ana Maria Aparecida Guaraldo ** Luiz Augusto Magalhães**

RSPUB9/409

Bastos, O. de C. et al. Suscetibilidade de Biomphalaria glabrata, variante albina, oriunda de Belo Horizonte, $M G$ à infecção por Schistosoma mansoni, parasita em condições naturais, de roedores silvestres do Vale do Rio Paraiba do Sul, SP (Brasil). Rev. Saúde públ., S. Patlo, 12:179-83, 1978.

Resumo: Comprova-se que, em condiçōes experimentais, a Biomphalaria glabrata, variante albina, originária de Belo Horizonte ( $M G)$ é suscetivel à infeção por linhagem de $\mathrm{S}$. mansoni isolada de roedores silvestres do Vale do Rio Paraiba do Sul, no Estado de São Panlo, Brasil. São sugeridas razóes procurando esclarecer a ocorrência da esquistossomose mansônica no Vale do Rio Paraiba do Sul, área geográfica em que ainda não foi encontrada B. glabrata, hospedeira intermediária do trematódeo $e$ onde se desenvolve intensamente $B$. tenagophila, espécie considerada menos suscetivel ao esquistossomo. São fornecidas informaçôes sobre a presença simultânea de duas linhagens de comportamento biológico diferente: a linhagem $H$, diretamente relacionada com o homem e a linhagem $S$, oriunda de roedores silvestres, ambas da mesma área geográfica.

UNITERMos: Schistosoma mansoni. Biomphalaria glabrata. Roedores.

I N T RODUÇ $\mathrm{A} O$

Bastos, 1 em 1975, ao infectar Biomphalaria tenagophila com linhagem de Schistosoma mansoni, isolada a partir de miracidios obtidos do fígado de roedores silvestres naturalmente parasitados, no Vale do Rio Paraíba do Sul, verificou ser a taxa de mortalidade, no grupo de moluscos infectados, equivalente a encontrada no grupo de moluscos nāo infectados e utilizados para controle.

Tal comportamento sugere ser satisfatória a adaptação da linhagen silvestre local ao hospedeiro intermediário, igualmente regional e reforça a teoria de Schwetz ' (1956), que admite ser a infecção esquistossomótica nos roedores anterior

* Trabalho realizado com a colabojacão da FAPESP e CNPa.

* Do Instituto de Biologia da tnjeamp. Caixa Postal 1170 - 131mo - Campmas. SP Brasil. 
BASTOS, $O$. de $C$. et al. Suscetibiliaade de bumphalaria glabrata, variante albina, oriunda de Belo Horizonte, MG, à infecção por Schistosoma mansoni, parasita em condições naturais, de roedores silvestres do Vale do Rio Paraíba do Sul, SP (Brasil). Rev. Saúde pübl., S. Paulo, 12:179-83, 1978.

a do homem. Este autor assinalou que, em roedores silvestres naturalmente parasitados, o parasitismo crônico apresenta baixa patogenicidade. Tais verificações permitem sugerir que o $S$. mansoni de roedores silvestres apresenta nocividade atenuada, tanto ao roedor como ao molusco.

Com a finalidade de obter esclarecimentos sobre as relaçōes parasito-hospedeiro, utilizando a linhagem silvestre do Vale do Rio Paraiba do Sul, procurou-se verificar a possibilidade de tal linhagem parasitar espécimens de Biomphalaria glabrata de Belo Horizonte. Normalmente, segundo Paraense e Corrêa ${ }^{3,4}$ (1963), estes molus$\cos$ são resistentes à infecção pelas linhagens paulistas de $S$. mansoni, não informando, entretanto, a origem destas linhagens quanto ao hospedeito definitivo

\section{MATERIAL E METODOS}

a) Isolamento da linhagem silvestre de S. mansoni (linhagem $S$ )

Esta linhagem foi isolada a partir de miracídios obtidos de ovos no fígado de roedores silvestres naturalmente infectados e capturados no Vale do Rio Paraiba do Sul. Previamente, constatava-se a infecção parasitária por meio do exame de fezes do roedor. A identificação dos hospedeiros foi efetuada pelo Prof. Dr. Fernando Dias de Ávila Pires, do Departamento de Zoologia da Unicamp.

\section{b) Moluscos utilizados e sua proce- dência}

Foram utilizadas duas espécies de planorbídeos: Biomphalaria glabrata, variante albina, criada no laboratório e descendente de espécimes colhidos em Belo Horizonte (MG) e Biomphalaria tenagophila, também mantida no laboratório e descendente de espécimes colhidos no município de São José dos Campos (SP), no Vale do Rin Paraíba do Sul.

\section{c) Infeção dos moliisios}

Foram utilizadas duas técnicas para a infecção dos moluscos: "exposição individual" e "exposição em massa" (Standen,s 1952). Na "exposição individual", cada molusco foi submetido a infecção de 100 miracídios; na "exposição em massa", calcularam-se, aproximadamente, 20 miracídios para cada molusco.

\section{d) Obtenção de cercárias}

Decorridos quarenta dias, a contar da data da infecção, os moluscos eram expostos, semanalmente, à ação da luz e calor emanados de lâmpada elétrica, conforme a técnica preconizada por Pellegrino e Macedo ${ }^{\overline{1}}(1955)$.

\section{RESULTADOS}

Dezessete exemplares de $B$. tenagophila foram submetidos, pela técnica de "exposição em massa", a 340 miracídios (portanto, em média, 20 para cada caramujo) isolados de $Z$. brachyurus. Nesta prova verificou-se ser de $23,53 \%$ a taxa de infecção dos planorbideos.

Em experimento com B. glabrata, no qual 65 exemplares foram submetidos, por "exposição em massa", a 1.300 miracídios oriundos de $H$. b. leucogaster (em média, 20 para cada molusco), obteve-se a taxa de $4,65 \%$ de infecção.

Entretanto, como em observaçōes anteriores realizadas neste laboratório os caramujos submetidos a técnica de "infecção individual" apresentaram taxas de infecção maiores quando comparadas com os resultados obtidos pela utilização da técnica de "infecção em massa", resolveu-se submeter 29 exemplares de $B$. glabrata (utilizando a "exposição individual") à miracidios oriundos de $H . b$. leucogaster, numa proporção de 100 miracídios por molusco. Nesta 
BASTOS, $O$. de $c$. et al. Suscetibilidade de Biomphalaria glabrata, variante albina, oriunda de Belo Horizonte, MG, à infecção por Schistosoma mansoni, parasita em condiçôes naturais, de roedores silvestres do Vale do Rio Paraíba do Sul, SP (Brasil). Rev. Saúde públ., S. Paulo, 12:179-83, 1978.

experiência obteve-se uma taxa de infecção de $19,23 \%$, ficando assim confirmada a observação anteriormente relatada.

\section{DISCUSSÃO}

Paraense e Corrêa ${ }^{3,4}$ (1963), demonstraram a resistência de $B$. glabrata e de $B$. tenagophila à infecção cruzada, relativamente às linhagens de $S$. mansoni procedentes, respectivamente, de Belo Horizonte (MG) e do Vale do Rio Paraiba do Sul (SP).

Entretanto, a pesquisa apresentada neste trabalho, em que se utilizou linhagem de S. mansoni de roedores silvestres, dá ensejo a considerações que são a seguir apresentadas.

A presença de esquistossomose mansônica no Vale do Rio Paraíba do Sul é de recente verificação; por motivos óbvios, ela foi constatada primeiramente no homem e posteriormente nos roedores silvestres da regiāo.

A implantação da esquistossomose no Vale do Rio Paraíba do Sul (SP), onde nāo foi constatada, até agora, a presença de $B$. glabrata, pode ser imputada a duas circunstâncias essenciais: a grande $e$ incessante corrente migratória humana, procedente de Minas Gerais e do nordeste do País, trazendo, de modo contínuo, portadores do parasito e contribuindo para a poluição da área e a infecção de espécimes de $B$. tenagophila, embora seja reconhecida a baixa suscetibilidade da espécie aos miracídios de $S$. mansoni de linhagem "mineira”, que em condiçōes naturais é mantida por B. glabrata. Não há como deixar de se admitir como procedente a hipótese da presença de miracídios ocasionalmente préadaptados e com capacidade de se instalarem no molusco de São Paulo, embora de espécie considerada resistente à infecção pela linhagem "mineira" e dando, conseqüentemente, origem à linhagem SJ (São
José dos Campos) do Vale do Rio Paraiba do Sul.

Deve-se ressaltar que, na maioria dos trabalhos publicados pertinentes à infecção experimental de animais, os autores utilizaram cercárias de moluscos capturados no campo, sendo desconhecida a origem de tais cercárias, quanto ao hospedeiro definitivo responsável pela infecção natural do planorbideo.

Entretanto, Bastos 1 (1975) verificou diferenças de comportamento no hospedeiro intermediário ao lidar com a linhagem de S. mansoni oriunda de ovos de fezes humanas (linhagem $\mathrm{H}$ ) e a linhagem isolada a partir de miracídios provindos de ovos do fígado de roedores silvestres naturalmente infectados (linhagem S), embora as duas linhagens geograficamente tivessem idêntica origem: o Vale do Rio Paraiba do Sul. Este autor assinala que a infecção causada por miracidios da linhagem $S$ não afeta, significativamente, a sobrevida dos moluscos, permitindo sugerir melhor adaptação da linhagem $S$ ao hospedeiro intermediário.

Por outro lado, Santos ${ }^{6}$ (1972) e Dias ${ }^{2}$ (1976) verificaram, no Vale do Rio Paraíba do Sul, a ocorrência de roedores silvestres naturalmente parasitados por grande numero de esquistossomos. Particularmente, alguns roedores observados por Dias ${ }^{2}$ mantiveram-se, por longo tempo, no laboratório, em condição hígida aparente normal, até serem sacrificados.

Tais observações corroboram o ponto de vista de Schwetz $\tau$ (1956), de que os roedores silvestres suportam melhor o parasitismo pelo $S$. mansoni.

$O$ presente trabalho assinala que a linhagem silvestre $(\mathrm{S})$ de $S$. mansoni do Vale do Rio Paraíba do Sul adapta-se, em condições de laboratório, à $B$. glabrata de Belo Horizonte que, até então, tem se mostrado refratária à infecção pelo miracídio de São Paulo. 
B.sTOS, O. de C. et al. Suscetibilidade de Bımphalaria glabrata, variante aibina, oriunda de Belo Horizonte, MG, à inficção por Schistosoma manson, parasita em condições naturais, de roedores silvestres do Vale do Rio Paraíba co Sul, SP (Brasil). Rev. Saúde públ., S. Paulo, 12:179-83. 1978.

A linhagem silvestre (S) de $S$. mansoni utilizada neste trabalho foi obtida de miracidios provindos de duas espécies de roedores freqüentes na região: Zygodontomys brachyurus e Holochilus brasiliensis lettcogaster.

$H$. b. leucogaster é de hábitos semiaquáticos e $Z$. brachyurus é espécie de terreno enxuto e com contato restrito com coleções de água. Provavelmente a primeira espécie tem maior responsabilidade na disseminação da esquistossomose mansônica, como também é provável que $Z$. brachyurus apenas ocasionalmente encontra condições adequadas para o encadeamento do ciclo biológico do $S$. mansoni.

O fato de $Z$. brachyurus, $H$. b. leucogaster e $B$. tenagophila conviverem num mesmo biótopo é motivo bastante ponderável para se considerarem idênticas as cepas de $S$. mansoni isoladas em qualquer dos dois roedores, não obstante ser pacifico que $H$. b. leucogaster seja o mais frequiente hospedeiro do trematódeo.

Aparentemente, pelas informações disponíveis, as linhagens de $S$. mansoni isoladas por outros autores, no Vale do Rio Paraíba do Sul (linhagem SJ), devem se relacionar com o $S$. mansoni de origem humana (linhagem $\mathrm{H}$ ). Tal hipótese alicerça-se no fato de que tais amostras são isoladas de moluscos naturalmente infectados e colhidos em focos conhecidamente frequientados pelo homem. Esta hipótese explicaria a constatação frequiente feita por nós e outros autores da resistência à infecção cruzada entre as linhagens $\mathrm{SJ}$ e $\mathrm{BH}$. É lógico, entretanto supor que as áreas freqüentadas pelo homem o são também por espécies de roedores que acabam sendo parasitados, permitindo, desta forma, o encadeamento biológico da parasitose enzoótica.

Contudo, há razões ponderáveis que levam a admitir que as linhagens humana (H) e a oriunda de roedores silvestres (S) mantêm, de algum modo, um nitido grau de isolamento na natureza. Se assim não fosse, com o constante fluxo gênico, a que estariam sujeitas estas populações de esquistossomos, as características das duas linhagens não deveriam se manter.

Considerando-se o que acaba de ser exposto e levando-se em conta os resultados assinalados enste trabalho, é inegável a diferença de comportamento, de modo particular quanto à capacidade da infecção, dos miracídios da linhagem humana $(H)$ ou de roedor $(\mathrm{S})$.

Finalmente, não há como deixar de se admitir que estes curiosos aspectos da biologia, em diferentes linhagens de $S$. mansoni, são de importância epidemiológica e que, por isso, devem ser convenientemente estudados.

\section{CONCLUSÃo}

Considerando-se o experimento realizado, pode-se concluir ser $B$. glabrata, variante albina, da linhagem de Belo Horizonte e mantida em laboratório, suscetivel à infecção com miracidios de $S$. mansoni provenientes de roedores silvestres do Vale do Rio Paraiba do Sul (SP). 
BASTOS, $O$, de $C$, et al. Suscetibilidade de Biomphalaria glabrata, variante albina, oriunda de Belo Horizonte, MG, à infecção por Schistosoma mansom, parasita em cond1ções naturais, de roedores silvestres do Vale do Rio Paraíba do Sul, SP (Brasi1). Rer. Saude pübl., S. Paulo, 19:179-83, 1978.

RSPUB9 $/ 409$

Bastos, O. de C. et al. [Susceptibility of an albinic variant of Biomphalaria glabrata from Belo Horizonte $(M \dot{G})$, to infection by Schistosoma mansoni, from wild rodents of the Paraiba do Sul River Vailley] Rev. Saúde públ., S. Paulo, 12:179-83, 1978.

ABSTRACT: The present research confirms the susceptibility, in laboratory. conditions, of an albinic variant of Biomphalaria glabrata from Belo Horizonte (MG), to the infection with a sample of Schistosoma mansoni obtained from wild rodents of the Paraiba do Sul River valley, in the State of Saio Paulo, Brazil. This account seems to be important, since it is generally thought that $\mathrm{B}$. glabrata is not susceptible to samples of S. mansoni from the Paraiba do Sul River valley. In the discussion, some arguments are presented in an attempt to explain the establishment of Manson's schistosomiasis in the Paraiba do Sul River valley. a region where $\mathrm{B}$. glabrata is absent and where $\mathrm{B}$. tenagophila, a local species considered of weak susceptibility to the worm, is very frequent. Another matter discussed is the local existence of two strains of $\mathrm{S}$. mansoni with different biological behaviours, the $H$ strain of human origin and the $S$ strain of wild local rodents.

UNITERMS: Schistosoma mansoni. Biomphalaria glabrata. Rodents.

\section{REFERENCIAS BIBLIOGRAFICAS}

1. BAstos. O. de C. Estudo do comportamento parasitológico e imunológico das linhayens humaria e silvestre do Schistosoma mansoni Sambon, 1907. Campinas, 1975. [Dissertação de Mestrado - Instituto de Biologia da Unicamp]

2. DIAS. L. C. de S. Aspectos paritsitolóficos e ecologicos da esquistossomose mansônica no Vale do Rio Paraíba do Sul e na remresa de Americana Estado de Sāo Paulo, Brasil. Campinas, 1976. [Tese de Doutoramento - Instituto de Biologia da Unicamp]

3. PARAENSE, W. L. \& CORREA, L, R. Sobre a ocorrencia de duas raças biológicas do Schistosoma mansoni no Brasil. [Apresentado na $1^{\mathrm{a}}$ Reunião Anual da Sociedade Brasileira para o Progresso da Ciência. Campinas, 1963j

4. PARAENSE, W, L. \& CORREA, L. R. Variation in susceptibility of populations of Australorbis glabratus to a strain of Schistosoma mansone. Rev. Inst. Med. trop. S. Paulo, 5:15-22. 196::

5. PELlEGRINO. J. \& MACEDO, D, G. A simplified method for the concentration of cercariae. J. Parasit., 41:32930. 1955 .

6. SANTOS. L. dos Importância do l'ato seiragem na disseminação da esquistossomose humana. no vale do Paraíba (Estado de São Paulo). Clenc, Cult., S. Paulo, 24:352. 1972.

7. SCHWETz. J. Role of wild rats and domestic rats (Rattus rattus) in sehistosomiasis of man. Trans, roy. Soc. trop. Med. Hyg., 50:275-82, 1956.

8. STANDEN, O. D. Experimental infection of Australorbis glabratus with $S$. mansoni I. Individual and mass infection to temperature and season. Ann. trop Med. Parasit., 46:48-53, 1952

Recebido para publicąão em 22/08;19ri Aprovado para publicasāo em 25/10;19ri 